International Journal of Medicine \& Biomedical Sciences // www.intlmedbio.com

ORIGINAL ARTICLE $\quad$ ISSN: 2467-9151 OPEN ACCESS

\title{
Antibiotic Susceptibility Pattern of Urinary Isolates from a Tertiary Care Hospital in Kathmandu
}

\author{
Gyanendra Ghimire ${ }^{1,3 *}$, Sabita Bhatta ${ }^{1}$, Raina Chaudhary ${ }^{1}$, Binita Adhikari ${ }^{1}$, Manoj Pradhan ${ }^{1}$, Jayendra \\ Bajracharya $^{2} \&$ Y Ibotomba Singh ${ }^{1}$ \\ ${ }^{1}$ Department of Microbiology, Nepalese Army Institute of Health Sciences, College of Medicine, Kathmandu, Nepal \\ ${ }^{2}$ Department of Biochemistry, Nepalese Army Institute of Health Sciences, College of Medicine, Kathmandu, Nepal \\ ${ }^{3}$ Singhaniya University, Pacheribari, Jhunjhunu, Rajasthan, India
}

\begin{abstract}
Urinary tract infection (UTI) is the commonest clinical condition encountered by the clinicians worldwide. The present research was conducted to find out bacterial pathogens responsible for UTI and their antimicrobial susceptibility patterns. The study was done in the Department of Microbiology, Nepalese Army Institute of Health Sciences (NAIHS), Kathmandu, Nepal. Total 450 clean catched midstream urine (MSU) samples were collected, processed, identified and their susceptibility patterns to commonly used antimicrobial agents were recorded according to the CLSI (Clinical Laboratory Standard Institute) guidelines. Out of 450 samples, $108(24.0 \%)$ showed bacterial growth in which UTI occurred more in female with 84 isolates $(77.8 \%)$ than in male $24(22.2 \%)$. Escherichia coli was the predominant bacterial isolate and accounted for $80(74.1 \%)$ of the total UTI cases followed by Klebsiella pneumoniae $11(10.2 \%)$, Proteus mirabilis 5 (4.6\%), Pseudomonas aeruginosa 4 (3.7\%), Staphylococcus aureus 4 (3.7\%), Staphylococcus saprophyticus $2(1.9 \%)$, and Enterococcus species 2 (1.9\%). The isolates were more sensitive to cefotaxim, amikacin, ofloxacin and norfloxacin. Most of the strains isolated were resistant to ampicillin, nalidixic acid, nitrofurantoin, cotrimoxazole followed by ciprofloxacin and gentamycin. The resistant patterns of urinary isolates with 3rd generation cephalosporin are increasing due to irrational and empirical use of antibiotics.
\end{abstract}

Keywords: UTI, Antibiotic susceptibility pattern, Escherichia coli

\section{INTRODUCTION}

Urinary tract infection (UTI) is a bacterial infection most frequently found in women and with greater frequency in older than in younger women. It refers to both microbial colonization of the urinary tract and tissue invasion. Bacteria are most commonly responsible for the infection [1]. UTI account for approximately $10 \%$ of OPD visits in case of women and $15 \%$ of women will have UTI at some time during their life. In pregnant women, the incidence of UTI can be as high as $8 \%$ [2]. It has been observed that 7 $\%$ of children with UTI develop renal scarring $[3,4]$. UTI is characterized by the presence of more than $10^{5} \mathrm{CFU} / \mathrm{ml}$ urine in the mid stream urine sample [5]. Pregnant women are at increased risk for UTI because of asymptomatic bacteriuria.
Antimicrobial agents are among the most commonly used and misused of all drugs. The growing awareness amongst the general public about antibiotics and their availability across the counter has given scope for misuse and emergence of resistance to some of the so called new generation of antibiotics. Antibiotics are usually given empirically before the laboratory results of urine cultures are available. To ensure appropriate therapy, current knowledge of the organisms that cause UTI and their antibiotic susceptibility is mandatory [6].

* Correspondence: Gyanendra Ghimire

Ph.D. Scholar, Singhaniya University, Pacheribari, Jhunjhunu,

Rajasthan, India

E-mail: serratia7@gmail.com 
If untreated, bacteriuria in pregnancy leads to either asymptomatic or symptomatic UTI. During pregnancy reduction in immunity encourages both commensal and non-commensal microorganisms, to increases the plasma volume and decrease the urine concentration and develop the glucosuria which encourages bacterial growth in the urine [7].

Escherichia coli remained the most common causative agent of uncomplicated UTI for many years with $75-90 \%$ causes of UTI infection. Klebsiella pneumoniae accounts for second highest organisms. The other Gram negative pathogens causing UTI are Proteus mirabilis and Pseudomonas aeruginosa, however, Enterococci sp and Staphylococcus saprophyticus are the most frequently encountered Gram positive bacteria in UTI [7,8].

To ensure appropriate therapy, current knowledge of the organisms that cause UTI and their antibiotic susceptibility testing is mandatory. Due to rising antibiotic resistance among uropathogens, it is important to have local hospital based knowledge of the organisms causing UTI and their antibiotic sensitivity patterns [8].

Hence the present study serves to know the prevalence of common pathogens and their antimicrobial susceptibility pattern in a tertiary care hospital.

\section{METHODOLOGY}

This study was carried out in the department of Microbiology, Nepalese Army Institute of Health Sciences (NAIHS), Kathmandu, Nepal to isolate the UTI pathogens and determine their antibiotic susceptibility pattern. A total of 450 mid-stream urine (MSU) samples were collected randomly in a sterile, wide mouthed container from the patients who attended the hospital with a suspected case of UTI during the period of January 2014 to December 2014. Urine samples were collected before antibiotic therapy was started and processed according to the Clinical laboratory standard institute (CLSI) guidelines [9].

Samples showing more than $10^{5} \mathrm{CFU} / \mathrm{ml}$ of urine were considered as significant and were subjected to antibiotic susceptibility testing by Modified Kirby Bauer's disc diffusion technique as recommended by CLSI guidelines $[9,10]$. The antibiotics used were amikacin, ampicillin, cefotaxime, ciprofloxacin, co-trimoxazole, gentamycin, nalidixic acid, nitrofurantoin, norfloxacin, ofloxacin ( $\mathrm{Hi}-$ Media, India).

\section{RESULTS}

Out of total 450 clean catched midstream urine (MSU) samples, $108(24.0 \%)$ samples showed bacterial growth. In the present study UTI occurred more in females than in males, comprising $84(77.8 \%)$ and $24(22.2 \%)$ respectively (Table-1).

Table 1. Prevalence of UTI in different age and sex groups

\begin{tabular}{|c|c|c|c|c|}
\hline $\begin{array}{c}\text { Age group } \\
\text { (years) }\end{array}$ & Male & Female & $\begin{array}{c}\text { Total } \\
(\mathrm{n}=108)\end{array}$ & Percentage \\
\hline $0-10$ & 2 & 3 & 5 & 3.7 \\
\hline $11-20$ & 0 & 7 & 7 & 6.5 \\
\hline $21-30$ & 0 & 21 & 21 & 19.4 \\
\hline $31-40$ & 2 & 32 & 36 & 33.3 \\
\hline $41-50$ & 7 & 13 & 21 & 19.4 \\
\hline $51-60$ & 13 & 8 & 19 & 17.6 \\
\hline Total & 24 & 84 & 108 & \\
\hline
\end{tabular}

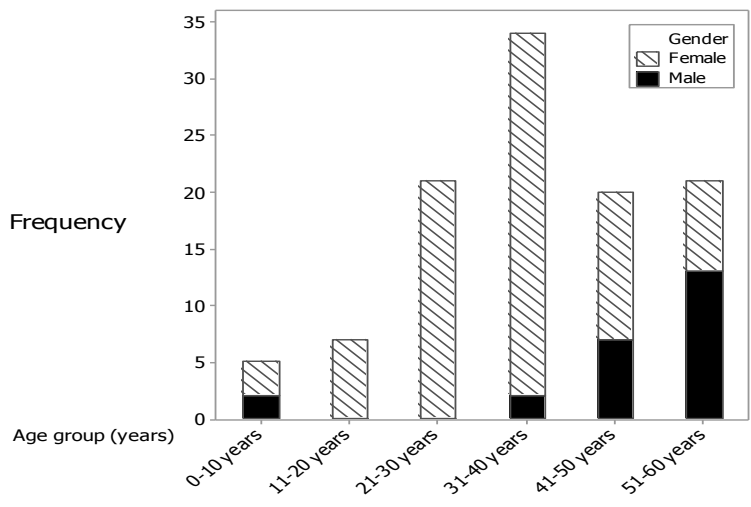

Figure 1. Prevalence of UTI in different age and sex groups

Escherichia coli was the commonest bacteria isolates 80 (74.1\%), followed by Klebsiella pneumonia 11(10.2\%), Proteus mirabilis 5 (4.6\%) Pseudomonas aeruginosa 4 (3.7\%), Staphylococcus aureus 4 (3.7\%), Staphylococcus saprophyticus 2 (1.9\%), and Enterococcus species 2 (1.9\%). (Table -2)

Table 2. Bacterial isolates from UTI cases

\begin{tabular}{|l|c|}
\hline Organisms & $\begin{array}{c}\text { Total isolates } \\
\mathrm{n}=108(24.0 \%)\end{array}$ \\
\hline Escherichia coli & $80(74.0 \%)$ \\
\hline Klebsiella pneumoniae & $11(10.2 \%)$ \\
\hline Proteus mirabilis & $5(4.6 \%)$ \\
\hline Pseudomonas aeruginosa & $4(3.7 \%)$ \\
\hline Staphylococcus aureus & $4(3.7 \%)$ \\
\hline Staphylococcus saprophyticus & $2(1.9 \%)$ \\
\hline Enterococcus species & $2(1.9 \%)$ \\
\hline
\end{tabular}


Table 3. Sensitivity patterns of isolated organisms to commonly used antibiotics

\begin{tabular}{|c|c|c|c|c|c|c|c|c|c|c|c|c|}
\hline \multirow{2}{*}{ Antibiotics } & \multirow{2}{*}{$\begin{array}{c}\text { Conc } \\
\text { (in mcg } \\
\text { /disc) }\end{array}$} & \multicolumn{3}{|c|}{$\begin{array}{l}\text { Zone of Inhibition } \\
\text { (mm) }\end{array}$} & \multirow{2}{*}{ E. coli } & \multirow{2}{*}{$\begin{array}{l}\text { Klebsiella } \\
\text { sp. }\end{array}$} & \multirow{2}{*}{$\begin{array}{l}\text { Proteus } \\
\text { sp. }\end{array}$} & \multirow{2}{*}{$\begin{array}{c}P . \\
\text { aeruginosa }\end{array}$} & \multirow{2}{*}{$\begin{array}{c}S . \\
\text { aureus }\end{array}$} & \multirow{2}{*}{$\begin{array}{c}\text { S. } \\
\text { saprophyticus }\end{array}$} & \multirow{2}{*}{$\begin{array}{c}\text { Enterococcus } \\
\text { sp. }\end{array}$} & \multirow{12}{*}{$\begin{array}{l}\mathrm{R}=\text { Resistance } \\
\mathrm{I}=\text { Intermediate } \\
\mathrm{S}=\text { Sensitive } \\
\mathrm{ND}=\text { Not Done } \\
\mathrm{E}=\text { Escherichia } \\
\mathrm{S}=\text { Staphylocuccus }\end{array}$} \\
\hline & & $\mathrm{R}$ & I & $\mathrm{s}$ & & & & & & & & \\
\hline Ampicillin & 10 & 13 & 18 & 19 & 85.50 & 95.00 & 95.00 & 35.0 & 50.00 & 40.00 & 20.0 & \\
\hline Ciprofloxacin & 5 & 15 & $16-20$ & 21 & 00.00 & 15.20 & 10.00 & 35.50 & 30.00 & 35.00 & 5.20 & \\
\hline Nalidixic acid & 30 & 13 & $14-18$ & 15 & 30.00 & 40.00 & 7.00 & 31.10 & 15.00 & 29.00 & 25.00 & \\
\hline Nitrofurantoin & 300 & 14 & $15-16$ & 17 & 88.10 & 55.00 & 35.00 & 31.00 & 89.00 & ND & 71.00 & \\
\hline Cotrimoxazole & 25 & 10 & $11-15$ & 16 & 35.00 & 50.00 & 07.00 & ND & 28.00 & 20.0 & 10.0 & \\
\hline Amikacin & 30 & 14 & $15-16$ & 17 & 87.00 & 97.00 & 95.00 & 30.00 & 55.00 & 42.00 & 20.00 & \\
\hline Gentamycin & 10 & 12 & $13-14$ & 15 & 65.00 & 72.00 & 28.0 & 30.00 & 65.00 & 35.00 & 50.00 & \\
\hline Norfloxacin & 10 & 12 & $13-16$ & 17 & 33.00 & 25.00 & 25.0 & 40.00 & 35.10 & ND & 15.20 & \\
\hline Ofloxacin & 5 & 12 & $15-17$ & 18 & 35.00 & ND & ND & ND & 49.00 & 45.50 & 09.10 & \\
\hline Cefotaxime & 30 & 14 & $15-22$ & 23 & 30.10 & 65.00 & 70.40 & 25.00 & 65.00 & 25.1 .0 & 36.00 & \\
\hline
\end{tabular}

Antibiotic sensitivity test was carried out on the basis of past experiences with type of organism and it's sensitivity. The isolates were more sensitive to cefotaxim, amikacin, ofloxacin and norfloxacin. Most of the strains isolated were resistant to ampicillin and nalidixic acid, nitrofurantoin, cotrimoxazole followed by ciprofloxacin and gentamycin. (Table-3).

The resistant pattern of urinary isolates with $3^{\text {rd }}$ generation Cephalosporin are increasing due to irrational and repeated use of antibiotics.

\section{DISCUSSION}

This study evaluated the causative agents of UTI and their antimicrobial susceptibility patterns in urine samples obtained from a tertiary care hospital of Kathmandu, Nepal. In our study the total growth positive rate $(24.0 \%)$ was observed. Similar result was noted in a study done by Kumari et al with a prevalence of $25.7 \%$ [3]. The findings are slightly higher in comparison to the findings from Chhetri et al (21.8\%) [11] and Raza S et al (19.7\%) [12]. The result is much higher in comparison to the findings from Akram et al (10.8\%) from India [13]. However, the findings are much less in comparison to the study conducted by Rai et al (37.4\%) in Kathmandu, Nepal [14]. Almost similar observation was found in a study done by Rama Prasad et al in India [15]. In the present study UTI occurred more in females than in males. Of the 108 isolates obtained $84(77.8 \%)$ were from females while 24 $(22.2 \%)$ were from males.
The study showed that UTI is more common in females than males with a female to male ratio of $3.5: 1$. This is in agreement with other findings which stresses that UTI is more frequent in females than in males and this is presumably due to shorter and wider urethra. The anatomical proximity of the female urethral opening and vagina makes the former prone to trauma during sexual intercourse. Bacteria may also get easy access to urethra during pregnancy and child birth [16]. In general, UTI occur less frequently in men at all ages but the frequency increases with age. Among the males, 54.2\% isolates were from more than 50-year age group. This may be due to variety of risk factors such as benign prostrate hypertrophy, diabetes, and use of urinary catheter [17].

In this study E. coli $(74.1 \%)$ was the predominant bacterial pathogen followed by Klebsiella species, Proteus species and others. This was similar to other studies. In contrast to these findings, one study from Aurangabad showed Klebsiella as the commonest isolate followed by E. coli, P. aeruginosa and $S$. aureus. This may be due to the fact that the Klebsiella is one of the most important organisms causing nosocomial infection [18].

The antimicrobial sensitivity and resistance pattern may differ from community to community and hospital to hospital. Present study showed high rate of resistance to Ciprofloxacin for E. coli which is one of the most recommended drug for the treatment of UTI. This study is similar to the study conducted by Kumari et al [3]. This indicates that there is haphazard use of ciprofloxacin due to lack of antibiotic policy and quinolones are comparatively cheaper than the western world and are easily available across the counters. 
Current study showed higher rate of sensitivity towards aminoglycoside for E. coli, Klebsiella species and others. This study is reinforced by the study conducted by Mutate et al [19]. The study showed high degree of resistance to amipicillin, norfloxacin and co-trimoxazole. Cotrimoxazole in the present study was no longer found to be effective for UTI caused by $E$. coli. The above mentioned result correlated with the study done by Babypadhmini [20].

Indiscriminate use of antibiotic had led to the development of resistant strains. A better approach to control this is, judicious use of antibiotics, only after proper antibiotic susceptibility testing. In fact, the irrational and in appropriate use of antibiotics is responsible for the development of resistance of the Enterobacteriaceae family including E. coli. In addition, regular antimicrobial susceptibility surveillance is essential for area-wise monitoring of the resistance patterns. An effective national and state level antibiotic policy and draft guidelines should be introduced to preserve the effectiveness of the antibiotics and for better patient management.

Conclusively, resistance rates among common uropathogens continue to evolve and appear to be increasing towards commonly used antimicrobials especially to quinolones. Continued surveillance of resistance rates among uropathogens is needed to ensure appropriate recommendations for the treatment of the infections.

\section{CONCLUSION}

The resistance rates among common uropathogens continue to evolve and appear to be increasing towards commonly used antimicrobials especially to quinolones. Continued surveillance of resistance rates among uropathogens is needed to ensure appropriate recommendations for the treatment of the infections.

\section{COMPETING INTERESTS}

The authors declare that they have no competing interest

\section{AUTHOR CONTRIBUTIONS}

GG conceived and designed the study, did the lab work and drafted the manuscript. Y.I supervised, designed the protocol for the study. RC, SB, BA, MP did the laboratory work concerning sample collection, processing, identification of clinical isolates. JB did the statistical analysis.

\section{ACKNOWLEDGEMENTS}

The authors would like to acknowledge the patients who participated in this study by providing their sample. We also express our thanks to the laboratory staff of Department of Microbiology, Nepalese Army Institute of Health Sciences, Kathmandu, Nepal for their support during the study.

\section{REFERENCES}

1. Marahatta R, Acharya BD, Pradhan P, Rai SK, Choudhury DR.. Asymptomatic bacteriuria among pregnant women visiting Nepal Medical College Teaching Hospital, Kathmandu, Nepal. Nepal Med Coll J 2011; 13: 107-10.

2. Sandhyarani T, Jayrani K, Sai Ravikiran B, Naveen Kumar C, Janani S. Microbiological Profile and spectrum of drug susceptibility in asymptomatic bacteriuria among antenatal women.URJMS 2014;1:13-6.

3. Rai Kumari N, Ghimire G, Gharti Magar JK,Mohapatra TM, Rai A. Antibiogram pattern of isolates from UTI cases in Eastern part of Nepal. Nepal Med Coll J 2005;07: 116-8.

4. Winberg J, Bergstrom T and Hanson LA. Neve Gesichtspunkte Zur Harnwesinpektion mit E.coli.WschrKinderkeilk 1971;119 : 506-19.

5. Chaudhary R, Ojha CR, Sijapati K, Singh Sk.Bacterial Pathogen Responsible for Urinary Tract Infection. $M J S B H$ 2012; 11:13-6.

6. Yengkokpam C,Ingudham D, Singh YI, Jha BK. Antibiotic Susceptibility Pattern of Urinary Isolates in Imphal(Manipur), India. Nepal Med Coll J 2007;09: 170-2.

7. Girishbabu RJ, Shrikrishna R and Ramesh ST. Asymptomatic bacteriuria in pregnancy. Int J Biol Med Res 2011; 2: 740-2.

8. Asati RK and Sadawarte K. Prevalence and Antimicrobial Susceptibility Pattern of Klebsiella pneumonia Causing Urinary Tract Infection and issues Related to the Rational Selection of Antimicrobials. SJAMS 2013; 1: 395-9.

9. Collee JG, Fraser AJ, Marmion BP, Simmons A, editors.Mackie and MaCartney Practical Medical Microbiology $\left(14^{\text {th }}\right.$ ed.). New York: Churchill Living Stone 1996: 131-49.

10. Betty AF, Daniel FS, Alice SW.Overview of bacterial identification and strategies. In Bailley and Scott's Diagnostic Microbiology. $12^{\text {th }}$ ed, Philadelphia: Mosby 2002: 216-47. 
11. Chhetri PK, Rai SK, Pathak UN et al. Retrospective study on urinary tract infection at Nepal Medical College Teaching Hospital, Kathmandu. Nepal Med Coll J 2001;03: 83-5.

12. Raza S, Paney S, Bhatt CP. Microbial Analysis of the Urinary Isolates in Kathmandu Medical College Teaching Hospital, Kathmandu, Nepal. Kathmandu Univ Med J 2011; 36: 295-7.

13. Md Akram, Md Sahid and Ashad U Khan. Etiology and antibiotic resistance pattern of community acquired urinary tract infections in JNMC Hospital Aligarh, India. Ann Clin Microbiol Antimicrobiols 2007; 6: 4-10.

14. Rai CK, Pokharel BM and Sharma AP. A prospective study of antibiotic sensitivity profile of the organisms associated with clinical infections among the patients attending TU Teaching hospital. J Nepal Assoc Med Lab Sci 2001; 3: 136.

15. Ramaprasad AV, Jayaram $\mathrm{N}$ and Nageshappa G. Urine culture sensitivity pattern in a private laboratory setup. Indian J Pathol Microbiol 1993; 36 :119-23.

16. Theodere M. Prevalance and antibiogram of urinary tract infection among prison inmates in Niseria.Int'lj Microbiol 2007; 3: 266-70.

17. Hooton TM, Scholes D, Hughes JP et al. A prospective study of risk factors for symptomatic urinary tract infection in young women. New Engl J Med 1996; 335: 468-74.

18. Kumamoto Y, Tsukamoto T and Hirose T. Comparative studies on activities of antimicrobial agents against causative organisms isolated from patients with urinary tract infections. Japanese J Antibiotics 1998; 51 : 112-29.

19. Mutate AJ, Hak E, Schuriak CA et al. Resistance of Uropathogens in symptomatic urinary tract infections in Leon, Nicaragua. Int'l J Antimicrob Agents 2004; 23 : 5069.

20. Babypadmini S, Appalaraju B. Extended spectrum lactamases in urinary isolates of Escherichia coli and Klebsiella pneumonia - Prevalence and susceptibility pattern in a tertiary care hospital. Indian J Med Microbiol 2004; 22 : 172-4.

\section{Article History:}

Received: 25 June, 2016

Revised: 19 August, 29 October 2016

Accepted: 21 November, 2016

Published online: 4 January, 2017

\section{For Citation:}

Ghimire G, Bhatta S, Chaudhary R, Adhikari B, Pradhan P, Bajracharya J, Singh YI. Antibiotic Susceptibility Pattern of Urinary Isolates from a Tertiary Care Hospital in Kathmandu. International Journal of Medicine \& Biomedical Sciences. 2017; 2(1):1-5 